\title{
Randomised controlled trial of dual blockade of renin-angiotensin system in patients with hypertension, microalbuminuria, and non-insulin dependent diabetes: the candesartan and lisinopril microalbuminuria (CALM) study
}

\author{
Carl Erik Mogensen, Steen Neldam, Ilkka Tikkanen, Shmuel Oren, Reuven Viskoper, \\ Richard W Watts, Mark E Cooper for the CALM study group
}

Department of

Medicine, $\mathrm{M}$,

Kommunehospitalet,

University Hospital,

DK-8000 Aarhus C,

Denmark

Carl Erik Mogensen

professor of medicine

Rødovre Centrum

294, DK-2610,

Denmark

Steen Neldam

general practitioner

Helsinki University Hospital, Clinic of

Internal Diseases,

Helsinki, FIN-00029

HYKS, Finland

Ilkka Tikkanen

associate professor of

medicine (nephrology)

Barzilai Medical

Centre, Ashkelon,

Israel

Shmuel Oren

physician

Reuven Viskoper

physician

19 Oxford Terrace,

Port Lincoln, SA

5606, Australia

Richard W Watts

physician

Department of

Medicine,

University of

Melbourne

(Repatriation

Campus),

W Heidelberg,

Victoria 3084,

Australia

Mark E Cooper

professor of medicine

Correspondence to:

C E Mogensen

cem@afdm.au.dk

BMJ 2000;321:1440-4

\begin{abstract}
Objectives To assess and compare the effects of candesartan or lisinopril, or both, on blood pressure and urinary albumin excretion in patients with microalbuminuria, hypertension, and type 2 diabetes. Design Prospective, randomised, parallel group, double blind study with four week placebo run in period and 12 weeks' monotherapy with candesartan or lisinopril followed by 12 weeks' monotherapy or combination treatment.

Setting Tertiary hospitals and primary care centres in four countries (37 centres).

Participants 199 patients aged 30-75 years. Interventions Candesartan $16 \mathrm{mg}$ once daily, lisinopril $20 \mathrm{mg}$ once daily.

Main outcome measures Blood pressure and urinary albumin:creatinine ratio.
\end{abstract}

Results At 12 weeks mean (95\% confidence interval) reductions in diastolic blood pressure were $9.5 \mathrm{~mm}$ $\mathrm{Hg}(7.7 \mathrm{~mm} \mathrm{Hg}$ to $11.2 \mathrm{~mm} \mathrm{Hg}, \mathrm{P}<0.001)$ and 9.7 $\mathrm{mm} \mathrm{Hg}(7.9 \mathrm{~mm} \mathrm{Hg}$ to $11.5 \mathrm{~mm} \mathrm{Hg}, \mathrm{P}<0.001)$, respectively, and in urinary albumin:creatinine ratio were $30 \%(15 \%$ to $42 \%, \mathrm{P}<0.001)$ and $46 \%$ (35\% to $56 \%, \mathrm{P}<0.001)$ for candesartan and lisinopril, respectively. At 24 weeks the mean reduction in diastolic blood pressure with combination treatment (16.3 $\mathrm{mm} \mathrm{Hg}, 13.6 \mathrm{~mm} \mathrm{Hg}$ to $18.9 \mathrm{~mm} \mathrm{Hg}, \mathrm{P}<0.001$ ) was significantly greater than that with candesartan (10.4 mm Hg, $7.7 \mathrm{~mm} \mathrm{Hg}$ to $13.1 \mathrm{~mm} \mathrm{Hg}, \mathrm{P}<0.001$ ) or lisinopril (mean $10.7 \mathrm{~mm} \mathrm{Hg}, 8.0 \mathrm{~mm} \mathrm{Hg}$ to 13.5 $\mathrm{mm} \mathrm{Hg}, \mathrm{P}<0.001)$. Furthermore, the reduction in urinary albumin:creatinine ratio with combination treatment $(50 \%, 36 \%$ to $61 \%, \mathrm{P}<0.001)$ was greater than with candesartan $(24 \%, 0 \%$ to $43 \%, \mathrm{P}=0.05)$ and lisinopril $(39 \%, 20 \%$ to $54 \%, \mathrm{P}<0.001)$. All treatments were generally well tolerated.

Conclusion Candesartan $16 \mathrm{mg}$ once daily is as effective as lisinopril $20 \mathrm{mg}$ once daily in reducing blood pressure and microalbuminuria in hypertensive patients with type 2 diabetes. Combination treatment is well tolerated and more effective in reducing blood pressure.

\section{Introduction}

The role of inhibition of the renin-angiotensin system in preventing microvascular complications, particularly nephropathy, in patients with daibetes has been clearly shown. ${ }^{1-3}$ In many people with evidence of diabetic renal disease, however, angiotensin converting enzyme (ACE) inhibitors alone fail to achieve blood pressure targets. There is increasing evidence that angiotensin II (AII), the effector molecule of the renin- angiotensin system, can be generated not only by the ACE enzyme but also by other pathways including chymase. $^{4-6}$ The advent of angiotensin II type 1 (AT1) receptor blockers provides an alternative approach to blocking the renin-angiotensin system. These antagonists, however, block only one subtype of the angiotensin II receptor, the type 1 subtype, and in contrast with ACE inhibitors do not promote accumulation of vasodilatory substances such as bradykinin. In normal subjects, this combination has been shown to be effective at decreasing blood pressure. ${ }^{48} \mathrm{We}$ compared the effects of candesartan ${ }^{9}$ (a type 1 receptor blocker) and lisinopril ${ }^{10}$ on blood pressure and urinary albumin excretion and evaluated the effects of the combination of both drugs in patients with hypertension, microalbuminuria, and type 2 diabetes.

\section{Participants and methods}

This study has been described according to the CONSORT guidelines for the presentation of clinical trials. ${ }^{11}$ This randomised, double blind, double dummy study was performed in 37 centres (12 in Australia, nine in Denmark, four in Finland, and 12 in Israel) in patients with type 2 diabetes who were aged between 30 and 75 years old and had previously diagnosed hypertension and microalbuminuria.

We included patients if the urinary albumin:creatinine ratio was $2.5-25 \mathrm{mg} / \mathrm{mmol}$ and the diastolic blood pressure was 90-110 $\mathrm{mm} \mathrm{Hg}$ after two and four weeks of placebo treatment, respectively. Exclusion criteria were: body mass index $\geqslant 40 \mathrm{~kg} / \mathrm{m}^{2}$, systolic blood pressure $>200 \mathrm{~mm} \mathrm{Hg}$, non-diabetic cause of secondary hypertension, cardiovascular event in the past six months, serum creatinine concentration $\geqslant 130 \times 6 \mathrm{~d}$ $\mathrm{mol} / \mathrm{l}$ in women and $\geqslant 150 \times 6 \mathrm{~d} \mathrm{~mol} / 1$ in men, serum potassium concentration $>5.5 \mathrm{mmol} / \mathrm{l}$, glycated haemoglobin concentration $\left(\mathrm{HbA}_{1 c}\right)>10 \%$, pregnancy or potential pregnancy, and breast feeding.

After four weeks of placebo treatment, eligible patients were randomised to four treatment groups. Figure 1 gives details of the randomisastion and treatment. Consequently, half the patients received candesartan and half received lisinopril for the first 12 weeks. From 12 to 24 weeks, one third of the patients received candesartan alone, one third lisinopril alone, and one third the combination, unless patients had diastolic blood pressure below $80 \mathrm{~mm} \mathrm{Hg}$ at 12 weeks.

The patients attended the clinic for a total of nine study visits: at four and two weeks before randomisation, at randomisation (week 0), and at 1, 6, 12, 13, 18, and 24 weeks after randomisation. At each visit blood pressure was measured in the morning after five minutes of rest, about 24 hours after the previous drug 


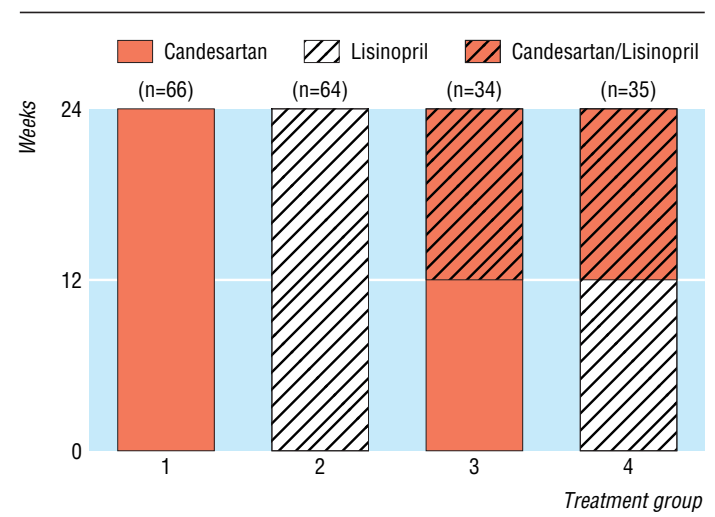

Fig 1 Distribution of participants in study. Doses were: candesartan $16 \mathrm{mg}$ once daily, lisinopril $20 \mathrm{mg}$ once daily, or their combination

administration, with an automatic device (Omron HEM-705 CP, Omron Electronics, Tokyo, Japan). Sitting blood pressure was measured three times with an interval of about two minutes, and the mean was calculated. The standing blood pressure was measured once after one minute of standing.

Microalbuminuria was determined two weeks before randomisation and at weeks 0,12 , and 24 by calculation of the urinary albumin:creatinine ratio. ${ }^{3}$ For each determination the patients brought early morning voided urine samples from two consecutive days. Albumin concentration was measured by immunoturbidimetry, and creatinine concentration was measured by autoanalyser. Creatinine clearance was calculated with the Cockroft-Gault formula $((140-$ age $) \times$ body weight $(\mathrm{kg}) \times \mathrm{K} /$ serum creatinine $(\mu \mathrm{mol} / \mathrm{l})$. K (constant) was 1.25 for men and 1.03 for women. Haemoglobin $A_{1 c}$ was measured by high performance liquid chromatography at weeks 0,12 , and 24 . Clinical chemistry, haematology, and urinalysis were performed at weeks 0,12 , and 24 with standard methods. Serum creatinine and potassium concentrations were also measured at weeks 1 and 13. The ACE genotype was determined as previously described. ${ }^{12}$ Tolerability was assessed by using spontaneously reported adverse events, recorded in response to an open question or observed by the investigator at each visit.

The study was performed in accordance with the principles stated in the Declaration of Helsinki and approval was obtained from each institution's ethics committee. All patients gave their informed consent before being included in the study.

\section{Statistical methods}

The assumed standard deviation for the change in urinary albumin excretion was 1.1 on a logged scale. This would allow estimation of the ratio of the expected medians with a relative error of at most $33 \%$ with a probability of $95 \%$. As we used the mean of two early morning measurements we predicted that the variability between indiviuals would be reduced. In consequence, the observed relative error could be expected to be smaller than assumed. We therefore calculated that we needed about 220 patients.

For all treatments we analysed the changes from baseline (randomisation) to 12 and 24 weeks in blood pressure, urinary albumin:creatinine ratio, and creatinine clearence with a linear model for analysis of covariance with factors for treatment, centre, and interaction between them and baseline value as a covariate. For urinary albumin:creatinine ratio the changes in diastolic blood pressure and body weight were also used as covariates. The urinary albumin: creatinine ratio was analysed after logarithmic transformation. Differences between treatments were estimated from the fitted model (analysis of covariance). The results for urinary albumin:creatinine ratio are presented as estimates of the true treatment geometric means and as estimates of the ratios of the true treatment geometric means, with their 95\% confidence intervals and corresponding $\mathrm{P}$ values. All analyses were based on intention to treat (defined as all patients who took at least one dose and had efficacy data available after randomisation), with the last value carried forward for missing values.

\section{Results}

As one randomised patient never took the study medication and for one other patient we had no efficacy data after randomisation there was a total of 197 evaluable patients.

\section{Effects on blood pressure and urinary albumin excretion}

After 12 weeks'treatment

Table 1 shows that there were no significant differences in baseline characteristics for the candesartan $(n=99)$

Table 1 Baseline characteristics of patients with hypertension, microalbuminuria, and type 2 diabetes followed from baseline to 12 weeks. Figures are means (SD) unless stated otherwise

\begin{tabular}{lcc} 
& Candesartan & Lisinopril \\
\hline No of patients & 99 & 98 \\
\hline Age (years) & $59.7(9.9)$ & $60.0(8.5)$ \\
\hline No of men & $66 / 33$ & $62 / 36$ \\
\hline Body mass index $\left(\mathrm{kg} / \mathrm{m}^{2}\right)$ & $30.7(4.3)$ & $29.8(3.8)$ \\
\hline Duration of hypertension (years) & $8.3(8.8)$ & $9.0(8.9)$ \\
\hline Duration of diabetes (years) & $9.8(7.5)$ & $8.4(7.3)$ \\
\hline Systolic blood pressure $(\mathrm{mm} \mathrm{Hg})$ & $162.7(17.7)$ & $162.6(17.6)$ \\
\hline Diastolic blood pressure $(\mathrm{mm} \mathrm{Hg})$ & $96.0(6.2)$ & $95.7(6.2)$ \\
\hline Urinary albumin:creatinine ratio $(\mathrm{mg} / \mathrm{mmol})^{\star}$ & $5.9(1.1)$ & $6.6(1.1)$ \\
\hline Serum creatinine $(\mu \mathrm{mol} / \mathrm{l})$ & $85.8(18.9)$ & $85.0(16.8)$ \\
\hline Creatinine clearance $(\mathrm{ml} / \mathrm{min})$ & $103.1(37.7)$ & $96.0(28.7)$ \\
\hline Haemoglobin $\mathrm{A}_{1 \mathrm{C}}(\%)$ & $7.6(1.2)$ & $7.6(1.6)$ \\
\hline ACE genotype $(\mathrm{DD} / \mathrm{ID} / \mathrm{ll} / \mathrm{not} \mathrm{known})$ & $28 / 45 / 14 / 12$ & $32 / 41 / 20 / 5$ \\
\hline
\end{tabular}

*Geometric mean (tolerance factors).

Table 2 Adjusted* mean reductions in blood pressure and urinary albumin:creatinine ratio from baseline to 12 weeks in patients with hypertension, microalbuminuria, and type 2 diabetes

\begin{tabular}{lccc} 
& Candesartan & Lisinopril & Adjusted mean difference between treatments \\
\hline Sitting diastolic blood pressure $(\mathrm{mm} \mathrm{Hg})$ & 9.5 (7.7 to 11.2$) ; \mathrm{P}<0.001$ & 9.7 (7.9 to 11.5); $\mathrm{P}<0.001$ & $0.2(-2.3$ to 2.7$) ; \mathrm{P}>0.20$ \\
\hline Sitting systolic blood pressure $(\mathrm{mm} \mathrm{Hg})$ & 12.4 (9.1 to 15.8$) ; \mathrm{P}<0.001$ & 15.7 (12.2 to 19.2$) ; \mathrm{P}<0.001$ & $3.3(-1.5$ to 8.2$) ; \mathrm{P}=0.18$ \\
\hline Urinary albumin:creatinine ratio $(\%)$ & 30 (15 to 42); $\mathrm{P}<0.001$ & 46 (35 to 56); $\mathrm{P}<0.001$ & 30 (1 to 71$) ; \mathrm{P}=0.058 \dagger$ \\
\hline
\end{tabular}

${ }^{\star}$ Adjusted for centre, treatment, baseline value, weight, and change in diastolic blood pressure.

†Relative reduction. 
and lisinopril $(n=98)$ groups. Eighteen in the candesartan group and 27 in the lisinopril group also received hydrochlorothiazide $12.5 \mathrm{mg}$ once daily. In both groups about $80 \%$ of the patients were taking oral antidiabetic drugs and 20\% were taking insulin. Both drugs reduced blood pressure and urinary albumin:creatinine ratio significantly from baseline to 12 weeks. Table 2 summarises the results.

\section{After 24 weeks treatment}

Table 3 show the baseline characteristics of the three groups followed to 24 weeks. Patients who were withdrawn from the study at the 12 week visit, mostly because their diastolic blood pressure was below 80 $\mathrm{mm} \mathrm{Hg}$, are not included in the 24 week analysis. After 24 weeks we had data for 49 in the candesartan group, 46 in the lisinopril group, and 49 in the combination group. A few patients in each treatment group also received hydrochlorothiazide $12.5 \mathrm{mg}$ once daily (candesartan $n=7$, lisinopril $n=6$, combination $n=6$ ).

Table 4 shows that all three treatments reduced both blood pressure and urinary albumin:creatinine ratio from baseline to 24 weeks, with the combination being the most effective. There was no significant difference in the reductions in systolic blood pressure observed after treatment with candesartan or lisinopril. The reductions in standing blood pressures were similar to the reductions in seated blood pressures.

Figure 2 shows mean systolic and diastolic blood pressure in the three treatment groups at different time points. In the group of patients who received the combination treatment after 12 weeks there was a measur-

Table 3 Baseline characteristics of patients with hypertension, microalbuminuria, and type 2 diabetes followed from baseline to 24 weeks. All figures are means (SD) unless stated otherwise

\begin{tabular}{|c|c|c|c|}
\hline & Candesartan & Lisinopril & $\begin{array}{l}\text { Candesartan } \\
\text { and lisinopril }\end{array}$ \\
\hline No of patients* & 66 & 64 & 67 \\
\hline Age (years) & $59.7(9.9)$ & $59.9(9.0)$ & $59.8(8.7)$ \\
\hline No of men & 48 & 43 & 37 \\
\hline Body mass index $\left(\mathrm{kg} / \mathrm{m}^{2}\right)$ & $31.0(4.2)$ & $29.6(3.7)$ & $30.2(4.2)$ \\
\hline $\begin{array}{l}\text { Duration of hypertension } \\
\text { (years) }\end{array}$ & $8.3(8.9)$ & $7.9(8.1)$ & $9.7(9.3)$ \\
\hline Duration of diabetes (years) & $10.0(7.7)$ & $8.3(7.0)$ & $9.1(7.7)$ \\
\hline $\begin{array}{l}\text { Systolic blood pressure } \\
(\mathrm{mm} \mathrm{Hg})\end{array}$ & $163.3(19.0)$ & $163.0(17.2)$ & $161.7(16.7)$ \\
\hline $\begin{array}{l}\text { Diastolic blood pressure } \\
(\mathrm{mm} \mathrm{Hg})\end{array}$ & $96.6(6.9)$ & $96.2(5.2)$ & $94.8(6.4)$ \\
\hline $\begin{array}{l}\text { Urinary albumin:creatinine ratio } \\
(\mathrm{mg} / \mathrm{mmol}) \dagger\end{array}$ & $7.2(1.1)$ & $5.9(1.2)$ & $5.6(1.1)$ \\
\hline Serum creatinine $(\mu \mathrm{mol} / \mathrm{l})$ & $88.3(18.5)$ & $85.6(16.7)$ & $82.4(18.1)$ \\
\hline Creatinine clearance $(\mathrm{ml} / \mathrm{min})$ & $103.5(38.4)$ & $96.8(28.9)$ & $98.4(32.9)$ \\
\hline Haemoglobin $A_{1 c}(\%)$ & $7.5(1.3)$ & $7.6(1.7)$ & $7.6(1.2)$ \\
\hline $\begin{array}{l}\text { ACE genotype (DD/ID/II/ } \\
\text { not known) }\end{array}$ & $18 / 32 / 8 / 8$ & $21 / 27 / 12 / 4$ & $21 / 27 / 14 / 5$ \\
\hline
\end{tabular}

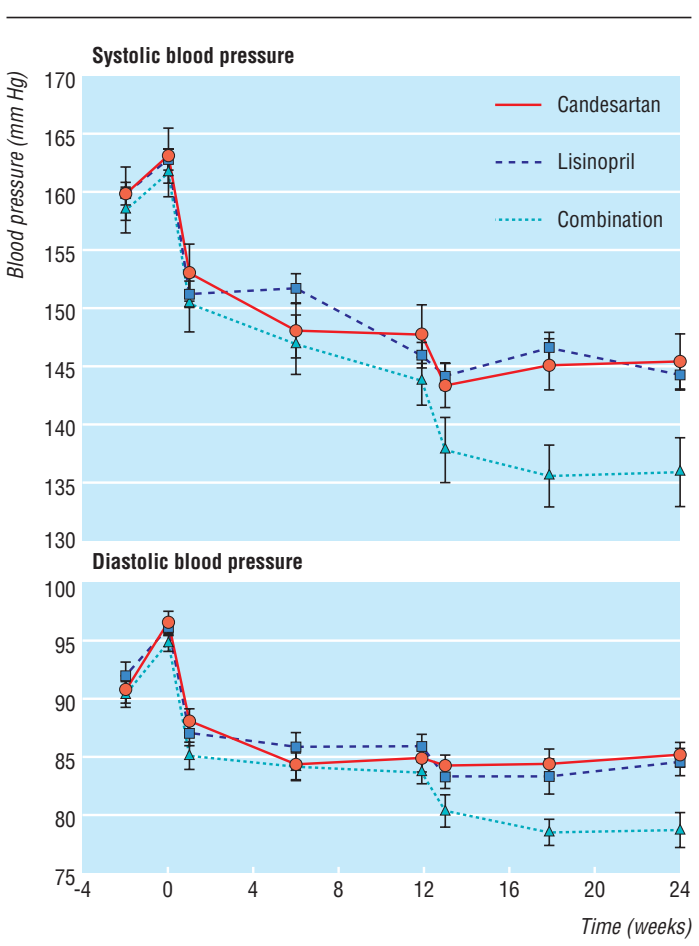

Fig 2 Mean (SE) seated systolic and diastolic blood pressure in patients with type 2 diabetes mellitus, hypertension, and microalbuminuria before and during treatment with candesartan $16 \mathrm{mg}$ once daily $(n=49)$, lisinopril $20 \mathrm{mg}$ once daily $(n=46)$, or combination of candesartan and lisinopril $(n=49)$. Combination group received monotherapy with either candesartan or lisinopril for first 12 weeks

able further reduction in both systolic and diastolic blood pressure. There was no significant influence of ACE genotype on response of either albuminuria or blood pressure to any of the treatments studied.

\section{Tolerability}

All treatment regimens were generally well tolerated. The most common adverse events during any of the treatment regimens were respiratory infection, cough, and headache, which occurred in less than $10 \%$ of the patients. Only 14 out of 197 randomised patients stopped treatment because of adverse events during the 24 week double blind period. Five patients discontinued because of dizziness or feeling weak, or both (two patients on candesartan, two on lisinopril, and one on the combination), while three patients discontinued because of cough (all treated with lisinopril). Other adverse events that caused patients to stop treatment occurred in single patients only.

There were no clear changes in mean values for haemoglobin $\mathrm{A}_{1 \mathrm{c}}$ or any routine laboratory variables from baseline to 12 or 24 weeks in any of the treatment groups. Slight increases of doubtful clinical significance

Table 4 Adjusted* mean reduction in blood pressure and urinary albumin:creatinine ratio from baseline to 24 weeks in patients with hypertension, microalbuminuria, and type 2 diabetes

Adjusted mean difference

\begin{tabular}{|c|c|c|c|c|c|}
\hline & \multirow[b]{2}{*}{ Candestartan } & \multirow[b]{2}{*}{ Lisinopril } & \multirow[b]{2}{*}{ Combination } & \\
\hline & & & & Combination $v$ candestartan & Combination $v$ lisinopril \\
\hline Sitting diastolic blood pressure $(\mathrm{mm} \mathrm{Hg})$ & 10.4 (7.7 to 13.1$) ; P<0.001$ & 10.7 (8.0 to 13.5$) ; P<0.001$ & 16.3 (13.6 to 18.9); $P<0.001$ & 5.9 (2.1 to 9.7$) ; P=0.003$ & 5.6 (1.7 to 9.4 ); $P=0.005$ \\
\hline Sitting systolic blood pressure $(\mathrm{mm} \mathrm{Hg})$ & 14.1 (8.9 to 19.2$) ; P<0.001$ & 16.7 (11.4 to 21.9); $P<0.001$ & 25.3 (20.3 to 30.3 ); $P<0.001$ & 11.2 (4.1 to 18.4 ); $P=0.002$ & 8.6 (1.4 to 15.9$) ; P=0.02$ \\
\hline Urinary albumin:creatinine ratio (\%) & 24 (0 to 43); $P=0.05$ & 39 (20 to 54 ); $P<0.001$ & 50 (36 to 61 ); $P<0.001$ & 34 (3 to 55); $P=0.04$ & $18(-20$ to 44$) ; P>0.20$ \\
\hline
\end{tabular}

${ }^{\star}$ Adjusted for centre, treatment, baseline value, weight, and change in diastolic blood pressure. 
were observed at 24 weeks in serum concentrations of creatinine $(8.1 \times 6 \mathrm{~d} \mathrm{~mol} / \mathrm{l})$, urea $(1.04 \mathrm{mmol} / \mathrm{l})$, potassium $(0.30 \mathrm{mmol} / \mathrm{l})$, and urate $(42.0 \times 6 \mathrm{~d} \mathrm{~mol} / \mathrm{l})$ in the group of patients treated with the combination treatment. In three patients, a significant increase in serum creatinine concentration was reported (two patients on candesartan, one on the combination), but these changes either resolved with continued treatment or were of only modest nature and did not require clinical intervention.

We observed no significant changes in mean creatinine clearance over 12 weeks in any of the treatment groups. Creatinine clearance was slightly decreased over 24 weeks in the groups treated with lisinopril (adjusted mean decrease $0.0835 \mathrm{ml} / \mathrm{sec}, \mathrm{P}=0.04)$ and the combination treatment $(0.0735 \mathrm{ml} / \mathrm{sec}, \mathrm{P}=0.05)$ but was not affected in the group treated with candesartan.

\section{Discussion}

We can confirm that dual blockade of the reninangiotensisn system, both at the level of ACE and at the level of the AII receptor, is associated with more effective reduction in blood pressure than observed with a single agent and that this observation extends to patients with diabetes. We cannot, however, determine from the present study if these further effects on urinary albumin excretion relate to more effective reduction in blood pressure or to more complete blockade of the renin-angiotensin system. Our results provide additional evidence for a role for agents which interrupt the renin-angiotensin system in conferring renoprotective effects in patients with incipient diabetic nephropathy.

Our results are consistent with experimental data that emphasise the central role of interruption of the renin-angiotensin system in mediating the renoprotective effects of ACE inhibitors. ${ }^{13}$ We cannot exclude that the similarity in effects between ACE inhibitors and AII receptor antagonists relates primarily to their similar effects on blood pressure. Previous studies in patients with hypertension, microalbuminuria, and type 2 diabetes, however, have suggested that part of the effects on albuminuria of agents that interrupt the renin-angiotensin system relate specifically to blockade of this vasoactive hormone pathway. ${ }^{14}$ One of our main findings was the ability of the combination of lisinopril and candesartan to reduce blood pressure by about $8 \mathrm{~mm} \mathrm{Hg}$ more than a single agent. Higher doses of a single agent would probably not have achieved similar effects on blood pressure. ${ }^{15}{ }^{16}$ Effect is not related to ACE genotypes. ${ }^{17-19}$

The role of dual blockade of the renin-angiotensin system has been explored in other clinical contexts with positive results. ${ }^{70}$ In a study of seven diabetic patients, losartan was added to ACE inhibitor for seven days. ${ }^{21}$ This had no effect on proteinuria, blood pressure, or renal function. By contrast, positive effects were observed in a trial of 4 weeks' duration in normotensive subjects with IgA nephropathy. ${ }^{22}$

Our study provides evidence of an important role for combination therapy in patients with type 2 diabetes and incipient nephropathy as this treatment is effective at reducing blood pressure, has a beneficial effect on albuminuria, and is associated with an

\section{What is already known on this topic}

Raised blood pressure is a strong risk factor for microvascular and macrovascular disease in patients with type 2 diabetes, and microalbuminuria adds to this risk

\section{What this study adds}

Angiotensin converting enzyme inhibitors and angiotensin receptor blockers both reduce blood pressure and microalbuminuria in these patients

Dual blockade of the renin-angiotensin system is more effective in reducing blood pressure and, to some extent, albuminuria

excellent safety profile. The safety of such a combination has recently been shown in a multicentre study evaluating the effects of the combination of valsartan and benazepril in patients with chronic renal impairment. ${ }^{23}$

There was a tendency for glomerular filtration rate, as assessed by the Cockroft-Gault formula, to decline with ACE inhibition but not with AII receptor antagonism. It has been previously suggested that ACE inhibitors may have different acute effects on renal haemodynamics to AII antagonists and that this may partly be bradykinin dependent. ${ }^{24}{ }^{25}$

Recent guidelines for blood pressure targets in diabetic patients have emphasised the importance of aggressive blood pressure reduction in diabetic patients with evidence of renal disease. ${ }^{26-28}$ Our results show that dual blockade of the renin-angiotensin system is particularly effective in decreasing blood pressure in these patients, and support this new and potentially highly beneficial therapeutic approach for the prevention of diabetic renal and vascular disease. ${ }^{29} 30$

Contributors: CEM had the idea for dual blockade, coordinated and designed the study, and is the guarantor. $\mathrm{SN}$ was the major coordinator in Denmark, IT was the major coordinator in Finland and contributed to writing the manuscript, SO and RV were the major coordinators in Israel, and RWW and MEC were the major coordinators in Australia. MEC was also involved in the statistical analyses. The paper was written mainly by CEM and MEC with the support of the other authors.

Competing interests: CEM and MEC have received fees for speaking at symposia supported by AstraZeneca, the manufacturers of lisinopril and candesartan cilexetil. CEM has received funds for research and consulting fees from AstraZeneca.

Funding: AstraZeneca, Mölndal, Sweden.

1 Cooper ME. Pathogenesis, prevention and treatment of diabetic nephropathy. Lancet 1998;352:213-9.

2 Mathiesen ER, Hommel E, Hansen HP, Smidt UH, Parving HH Randomised controlled trial of long term efficacy of captopril on preservation of kidney function in normotensive patients with insulin dependent diabetes and microalbuminuria. BMJ 1999;319:24-5.

3 Mogensen CE, Keane WF, Bennett PH, Jerums G, Parving HH, Passa P, et al. Prevention of diabetic renal disease with special reference to microalbuminuria. Lancet 1995;346:1080-4.

4 Azizi M, Chatellier G, Guyene TT, Murietageoffroy D, Menard J. Additive effects of combined angiotensin-converting enzyme inhibition and angiotensin II antagonism on blood pressure and renin release in sodium-depleted normotensives. Circulation 1995;92:825-34.

5 Hollenberg NK, Fisher NDL, Price DA. Pathways for angiotensin II generation in intact human tissue-evidence from comparative pharmacological interruption of the renin system. Hypertension 1998;32:387-92.

6 Johnston CI. Angiotensin receptor antagonists: focus on losartan. Lancet Johnston CI. Angio

7 Azizi M, Guyene TT, Chatellier G, Wargon M, Menard J. Additive effects of losartan and enalapril on blood pressure and plasma active renin. Hypertension 1997;29:634-40.

8 Schmitt F, Natov S, Martinez F, Lacour B, Hannedouche TP. Renal effects of angiotensin I-receptor blockade and angiotensin convertase inhibition in man. Clin Sci 1996:90:205-13. 
9 McClellan KJ, Goa KL. Candesartan cilexetil-a review of its use in essential hypertension. Drugs 1998;56:847-69.

10 EUCLID study group. Randomised placebo-controlled trial of lisinopril in normotensive patients with insulin-dependent diabetes and normoalbuminuria or microalbuminuria. Lancet 1997;349:1787-92.

11 Begg C, Cho M, Eastwood S, Horton R, Moher D, Olkin I, et al. Improving the quality of reporting of randomized controlled trials. The ing the quality of reporting of randomized
CONSORT statement. JAMA 1996;276:637-9.

12 Badenhop RF, Wang XL, Wilcken DEL. Angiotensin-converting enzyme genotype in children and coronary events in their grandparents. Circulation 1995;91:1655-8.

13 Allen TJ, Cao Z, Youssef S, Hulthen UL, Cooper ME. The role of angiotensin II and bradykinin in experimental diabetic nephropathy: functional and structural studies. Diabetes 1997:46:1612-8.

14 Agardh CD Garcia Puig J Charbonnel B, Angelkort B, Barnett AH. Greater reduction of urinary albumin excretion in hypertensive type II diabetic patients with incipient nephropathy by lisinopril than by nifedipine. J Hum Hypertens 1996;10:185-92.

15 Goa KL, Haria M, Wilde MI. Lisinopril-a review of its pharmacology and use in the management of the complications of diabetes mellitus. Drugs 1997;53:1081-105.

16 Sever PS. Clinical profile of the novel angiotensin II type I blocker candesartan cilexetil. J Hypertens 1997;15:S9-12.

17 Parving HH, Jacobsen P, Tarnow L, Rossing P, Lecerf L, Poirier O, et al. Effect of deletion polymorphism of angiotensin converting enzyme gene on progression of diabetic nephropathy during inhibition of angiotensin converting enzyme -observational follow up study. BMJ 1996;313:591-4.

18 Ritz E. Nephropathy in type 2 diabetes. J Intern Med 1999;245:111-26.

19 Marre M, Jeunemaitre X, Gallois Y, Rodier M, Chatellier G, Sert C, et al. Contribution of genetic polymorphism in the renin-angiotensin system to the development of renal complications in insulin-dependent diabetes. J Clin Invest 1997;99:1585-95.

20 Hamroff G, Katz SD, Mancini D, Blaufarb I, Bijou R, Patel R, et al. Addition of angiotensin II receptor blockade to maximal angiotensinconverting enzyme inhibition improves exercise capacity in patients with severe congestive heart failure. Circulation 1999;99:990-2.
21 Hebert LA, Falkenhain ME, Nahman NS, Cosio FG, O'Dorisio TM. Combination ACE inhibitor and angiotensin II receptor antagonist therapy in diabetic nephropathy. Am J Nephrol 1999;19:1-6.

22 Russo D, Pisani A, Balletta MM, De Nicola L, Savino FA, Andreucci M, et al. Additive antiproteinuric effect of converting enzyme inhibitor and losartan in normotensive patients with IgA nephropathy. Am J Kid Dis 1999;33:851-6.

23 Ruilope LM, Aldigier JC, Ponticelli C, Oddou-Stock P, Botteri F, Mann JF, et al. Safety of the combination of valsartan and benazepril in patients with chronic renal disease. J Hypertens 2000;18:89-95.

24 Komers R, Cooper ME. Acute renal haemodynamic effects of angiotensin converting enyzme inhibition in diabetic hyperfiltration: the role of kinins. Am J Physiol 1995·268·F588-94.

25 Demeilliers B, Jover B, Mimran A. Contrasting renal effects of chronic administrations of enalapril and losartan on one-kidney, one clip hypertensive rats. J Hypertens 1998;16:1023-9.

26 Guidelines Subcommittee. 1999 World Health OrganizationInternational Society of Hypertension guidelines for the management of hypertension. J Hypertens 1999;17:151-83.

27 Joint National Committee on Prevention, Detection, Evaluation, and Treatment of High Blood Pressure. The sixth report of the joint national committee on prevention, detection, evaluation, and treatment of high blood pressure. Arch Intern Med 1997;157:2413-45.

28 Ramsay LE, Williams B, Johnston GD, MacGregor GA, Poston L, Potter $\mathrm{JF}$, et al. British Hypertension Society guidelines for hypertension management 1999: summary. BMJ 1999;319:630-5.

29 Chaturvedi N, Sjolie A-K, Stephenson JM, Abrahamian H, Kelpes M, Castellarin A, et al. Effect of lisinopril on progression of retinopathy in people with type 1 diabetes. Lancet 1998;351:28-31.

30 Heart Outcomes Prevention Evaluation (HOPE) Study Investigators. Effects of ramipril on cardiovascular and microvascular outcomes in people with diabetes mellitus: results of the HOPE study and MICRO-HOPE substudy. Lancet 2000;355:253-9.

(Accepted 26 June 2000)

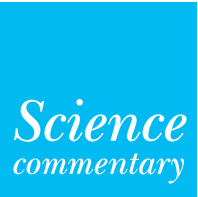

\section{Renal function-and how to assess it}

The gold standard test for assessing renal function is the glomerular filtration rate. ${ }^{1}$ Measuring this rate is a laborious process but is most useful for assessing renal function in patients whose serum creatinine concentration is at the upper limit of normal or in patients who develop early renal impairment secondary to treatment with non-steroidal anti-inflammatory drugs, lithium, or angiotensin converting enzyme inhibitors. The normal range is $80-120 \mathrm{ml} / \mathrm{min}$.

A useful and practical surrogate marker for the glomerular filtration rate is creatinine clearance. Creatinine clearance measures the ability of the kidneys to clear creatinine from the circulation into the urine over a period of 24 hours. This is a much more accessible measure of renal function, but because the serum creatinine concentration is influenced by muscle mass and age (it increases with muscle bulk and decreases with age), creatinine clearance rates must be interpreted for the individual patient. Body builders have a tendency for high creatinine concentrations while frail elderly women may have misleadlingly low concentrations.

Most clinicians use serum creatinine concentrations as the most practical measure of renal function. Normal creatinine concentrations can be obtained even when the glomerular filtration rate has dropped by $50 \%$, however, so it is fairly insensitive as an indicator of early renal insufficiency. Once serum creatinine concentrations are abnormal it can be assumed that there is measurable renal impairment (that is, more than half the filtering capacity of the kidneys has been lost).

Measuring the blood urea concentration alone also has limitations because it is influenced by protein metabolism, the state of dehydration, and the use of steroids, in addition to renal function. Thus patients with renal impairment can have relatively normal blood urea concentrations if they are grossly malnourished and not eating.

The Cockroft-Gault formula (mentioned in the paper) is a way of calculating the glomerular filtration rate without undertaking a 24 hour urine collection. The formula factors in age and body mass together with serum creatinine concentrations in an attempt to standardise the serum results and to be able to compare one person's renal function with another. It tends to be used more in research settings than in routine clinical practice as a way of improving the quality of data on renal function.

Abi Berger Science editor, BMJ

1 Cameron J, Greger R. Renal function and testing of function. In: Davison A, Cameron J, Grunfeld J-P, Kerr D, Ritz E, Winearls C, eds. Oxford textbook of clinical nephrology. 2nd ed. Oxford: Oxford Medical Publications, 1998.

\section{Endpiece}

Youth, day, old age and night

Youth, large, lusty, loving-youth full of grace, force, fascination,

Do you know that Old Age may come after you with equal grace, force, fascination?

Day full-blown and splendid-day of the immense sun, action, ambition, laughter,

The Night follows close with millions of suns, and sleep and restoring darkness.

Walt Whitman, 1881 